\title{
Editorials
}

\section{Who will grasp the public health nettle in London?}

London is approaching a crossroads in health policy. The May 1998 referendum on proposals for a Mayor and Assembly for London marked a significant step in the development of a level of city wide government that has been absent since the abolition of the Greater London Council 12 years earlier. A majority of Londoners voted to support an elected Mayor. The White Paper on the new style London Government ${ }^{1}$ will not only create Greater London's first elected Mayor and Assembly, it will mark what is seen by some as a new era in strategic governance across the capital. As the bill that creates a Greater London Authority (GLA), progresses through its committee stages there are important opportunities for embedding real public health goals in the fledgling legislation that should not be missed. While the GLA will not directly manage any health services, it will have a responsibility to promote the health of Londoners. More specifically the White Paper states "The Mayor would look at the effect on health of all his or her policies and functions, and would have a duty to promote the improvement of the health of Londoners". If this is translated into practice, it will place a duty on the Mayor to ensure that some of the key determinants of health in the capital - which fall to the GLA - such as transport, urban and environmental planning have health objectives at their heart.

The first issue concerns the ability to assess the health of the whole city. Above all else London is large and heterogeneous. The population of 7 million people, daily inflated by about $3 / 4$ million commuters from surrounding areas, is larger than many European countries. With around 4365 people per square kilometre, London is one of the most densely populated cities in Europe. The capital has often been described as a series of distinct villages with clear political power and autonomy vested in its 33 local authorities. Yet when thinking about public health there are significant areas where either the causes of ill health, or services to deal with these, need to be planned and provided across boundaries. For example only a minority of Londoners live and work in the same borough. In Westminster, only $10 \%$ of people working in the borough live there, and even in Outer London the equivalent figures only ever reach $50 \%$. When looking at the health implications of an issue such as transport policy or air quality, a local analysis alone does not make sense and there needs to be a London wide view. ${ }^{2}$ Even for issues such as employment and the local economy, the fortunes of areas within the city are bound up with the wider picture for the whole of London. Local actions are important-yet so is work at a London wide level.

In the past most action has been fragmented and cross London action exceptional rather than usual. Some of this is now changing. London's 16 Health Authorities now work more closely than hitherto within a new regional framework for London that is brought together by London's recently created Regional Office of the NHS Executive.

This will be further influenced by London's soon to be created Mayor and GLA who will together create a new strategic focus for the capital, its local authorities and some of the key determinants of health. In term of health services, London has been reviewed twice since 1992. The
Tomlinson Report ${ }^{3}$ and the more recent Turnberg Report ${ }^{4}$ have both advocated a more cohesive, London wide view of the equitable distribution of health care facilities and mental health services. Much however, still remains to be implemented. London now has a strong network of Directors of Public Health who, working with others, produced London's first Public Health Report ${ }^{5}$ for the whole city.

The attractions of any city, and especially the capital, for younger people in search of opportunity and employment makes inward migration an important factor in the make up of London and its health. Many of the capital's key health problems are linked to young people and the inner city. For example, sexual health problems are particularly acute in the capital, especially in relation to HIV/AIDS. Estimates suggest that one third of all homosexual men in the United Kingdom live within Inner London. It is estimated that in 199610000 adults with HIV infection were living in Inner London and 2000 in Outer London. ${ }^{6}$ HIV/AIDS related deaths have grown to become by far the most common cause of death in men aged $15-54$ in London, and especially inner London. The capital also holds a special place in terms of drug use and drug trafficking (estimates suggest that three quarters of all drug trafficking in the United Kingdom takes place within London). Some $4.7 \%$ of men in Inner London between ages 15-59 have reported injecting drugs at some time-higher than any other area in the United Kingdom.

London's severe acute mental health problems ${ }^{8}$ form a recurrent theme in reviews of health in the capital. Compared with other British cities, inner London, appears to have a higher proportion of adults requiring mental health services, especially men aged $15-45$, more children on "at risk registers", and four times as many patients in medium secure mental health units.

London is the most ethnically diverse of British cities. The 1991 Census shows that around $45 \%$ of all the United Kingdom's black and ethnic minority population lived within Greater London. ${ }^{9}$ This encompasses older established communities from the 50s and 60s together with newer migrants. Home Office estimates suggest that $85 \%$ of refugees coming into the United Kingdom settle in London. ${ }^{10}$

London is the hub for much political, financial and cultural activity within the country. Yet there is the paradox that alongside this concentration of power, glamour and wealth are some of the poorest and most deprived communities in the country. Extremes of deprivation mirror problems in other cities throughout the world. Yet the scale of London adds significance, for example the 1991 Census showed that within London there were more childrenover 324000 - living in households with no earning adults, more than the total population of many medium sized cities.

There are more people in London with high income levels, yet at the same time more with lower than average incomes. ${ }^{11}$ Moreover, the presence of those on high incomes can distort local economies in ways that further add to the disadvantage of the less wealthy. Nowhere is this more so than in the housing market 
where London combines the highest prices in the United Kingdom to rent and buy accommodation, with high levels of overcrowding and poor quality housing (see HOLP Housing Report). Though the exponential growth in homelessness in London, observed during the 1980s has been declining over the past few years, tackling homelessness still remains one of the most serious problems for London.

Analysis of changing mortality rates within London show that overall London is failing to keep pace with national trends. For conditions such as cardiovascular disease, where historically London has compared well with other urban centres in the United Kingdom, London is losing its advantage. ${ }^{12}$ Moreover, as with many other parts of the country, the health divide between rich and poor areas is increasing. ${ }^{13} 14$ The extent of health inequality across the city and in particular the ways future investment in regeneration fund for the inner city are targeted, is a critical issue for tackling some of the most serious health problems in the capital.

Finally, in terms of Health Services, numerous reviews have pointed to London's strengths as a research and teaching centre, and its weakness in terms of primary care. ${ }^{2}{ }^{3}$ Moreover the increased attention on commissioning at the level of Primary Care Groups (PCGs) is based on one if the weakest areas of health services in Londonwhich now has 66 PCGs.

Neither the Mayor, the Greater London Authority or a single Regional Office for London's new NHS will have a monopoly of answers to London's health issues. The size and complexity of the city and constituent parts will always produce problems. The welcome renewed focus on the health of the whole city should help us re-focus on the health divide. The proof of the pudding will be in future trends in London's many inequalities in health and its causes.

Health of Londoners Project

MARTIN BARDSLEY

BOBBIE JACOBSON
Health of Londoners Project and East London and The City Health Authority

Correspondence to: Dr B Jacobson, East London and The City Health Authority, 97-99 Bow Road, London E3 2AN.

1 Department of Environment Transport and the Regions. A mayor and assembly for London: The Government's proposals for modernising the governance of London. London: The Stationery Office, 1998

2 Health of Londoners Project. Transport in London and the implications for health. London: Health of Londoners project, 1996.

3 Tomlinson B. Report of the Inquiry into London's health services, medical education and research. London: HMSO, 1992.

4 Department of Health. Health services in London: A strategic review. London: Department of Health, 1998b.

5 Health Londoners Project. Health of Londoners. A public Health report for London. London: Kings Fund, 1998.

6 Hickman M, Bardsley M, De Angelis D, et al. A sexual health ready reckoner: Summary indicators of sexual behaviour and HIV in London and South East England. London: The Health of Londoners Project, 1997.

7 Wadsworth J, Hickman M, Johnson AM, et al.Geographical variation in sexual behaviour in Britain: implications for sexually transmitted disease epidemiology and sexual health promotion. AIDS 1996;10:193-9.

8 Johnson S, et al. London's mental health: The report to the King's Fund London Commission. London: King's Fund, 1997.

9 Storkey M. London's ethnic minorities: one city many communities. London: London Research Centre, 1994.

London Research Centre, 1994.
Carey-Wood J, Duke K, Karn V, et al. The settlement of refugees in Britain. Carey-Wood J, Duke K, Karn V, et al. The settlement of refugees in
Home Office research Study Number 141. London: HMSO, 1995.

11 Anderson H, Flatley J. Contrasting London incomes. London: London Research Centre, 1998.

12 Bardsley M, Basnett I, Congdon P, et al. Changing mortality rates in London: A review of the evidence. London: The Health of Londoners Project, 1997. 3 Congdon P. Socio-economic structure and health in London. Urban Studies 1995;32:523-49.

14 Bardsley M, Morgan D. Health. In: Edwards P, Flatley J, eds. The capital divided: mapping poverty and social exclusion in London. London: London Research Centre. 